\title{
Article
}

\section{Over egging the pudding? Comments on Ojala and Thorpe}

Collins, D.J., Collins, L., and Willmott, T.

Available at http://clok.uclan.ac.uk/12530/

Collins, D.J. ORCID: 0000-0002-7601-0454, Collins, L., ORCID: 0000-00027478-1140 and Willmott, T. (2016) Over egging the pudding? Comments on Ojala and Thorpe. International Sport Coaching Journal, 3 (1). pp. 90-93. ISSN 2328-918X

It is advisable to refer to the publisher's version if you intend to cite from the work. http://dx.doi.org/10.1123/iscj.2015-0068

For more information about UCLan's research in this area go to

http://www.uclan.ac.uk/researchgroups/ and search for < name of research Group>.

For information about Research generally at UCLan please go to http://www.uclan.ac.uk/research/

All outputs in CLoK are protected by Intellectual Property Rights law, including Copyright law. Copyright, IPR and Moral Rights for the works on this site are retained by the individual authors and/or other copyright owners. Terms and conditions for use of this material are defined in the policies page.

\section{CLoK}

Central Lancashire online Knowledge www.clok.uclan.ac.uk

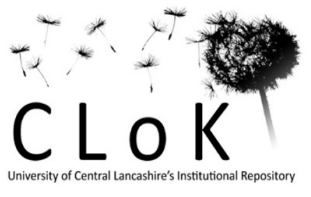


This is a pre-proof corrected manuscript, as accepted for publication, of an article published in International Sport Coaching Journal, CHuman Kinetics, in November 2015, available online: http://journals.humankinetics.com/iscj-in-press/iscj-in-press/over-egging-the-

pudding-comments-on-ojala-and-thorpe

\section{Over egging the pudding? Comments on Ojala and Thorpe}

David J. Collins ${ }^{1}$, Loel Collins ${ }^{1} \&$ Tom Willmott ${ }^{2}$

${ }^{1}$ Institute of Coaching and Performance, University of Central Lancashire

${ }^{2}$ Head Coach, Park and Pipe, Snowsports New Zealand, Wanaka, New Zealand

*Correspondence concerning this article should be addressed to Dave Collins, Institute of Coaching and Performance, University of Central Lancashire, Preston, PR1 2HE, United Kingdom. E-mail: DJCollins@ @uclan.ac.uk. 


\begin{abstract}
In a recent paper in ISCJ, Ojala and Thorpe offered a culturally based observation that questions the role and application of coaching in action sports. Their critique is focused on the action sport of snowboarding which, despite its' comparatively recent inclusion in the Olympics, retains a different, almost collaborative rather than competitive culture more akin to other action sports such as skateboarding and surfing. Ojala and Thorpe then present Problem Based Learning (PBL) as the solution to many of these perceived ills, describing the positive characteristics of the approach and promoting its cultural fit with action sport environments and performers. In this paper we offer a different perspective, which questions the veracity of the data presented and the unquestioningly positive view of PBL as the answer. Our alternative, data-driven perspective suggests that action sport athletes are increasingly positive, or even desirous of good coaching, of which PBL is a possible approach; suitable for some athletes some of the time.
\end{abstract}

Keywords: Coaching, action sports, adventure sports, Problem based learning 
2 Collins, 2012) or action (their term, which we will use throughout this paper) sports, we were

interested to read the paper on the role of the coach and the use of problem based learning by

Ojala and Thorpe (2015). We concur with their statement on the "unique value systems" which athletes may hold and also that "not all action sport athletes pursue careers via competition" (op cit., p. 65). Indeed, this was a crucial part of our own argument in examining the important influences of social milieu and culture in the support approaches used with performers (Willmott \& Collins, 2015). It is essential that the social and cultural context of a sport is carefully considered when developing appropriate support structures. Indeed, the structures and systems around coaching are themselves a social and cultural setting; a consideration when deciding on the optimum pathway for coach development, methodology and deployment (Stoszkowski \& Collins, 2014).

However, we do not agree and must take issue with the positions espoused in other aspects of their paper. Specifically, we feel that the picture presented of performer perceptions is limited and that the presentation of Problem Based Learning (hereafter PBL) lacks balance or criticality and misses an essential point of good coaching. We contend that good coaching is a decision making game (cf. Abraham \& Collins, 1998, 2011; Collins \& Collins, 2014, in press), and is holistic and inclusive in its methodology; in short, a single method of coaching is almost inevitably flawed for some purposes and the fundamental of good practice is the ability to select the right tool, at the right place and the right time to develop an individual performer. Accordingly, we present a short treatment of our counter position, in an attempt to stimulate debate.

\section{Counterpoint 1: Role of Coaching and Coaches in Action Sports}

We would be very interested to know which athletes made up the sample that the paper refers to as it sounds like it may be dominated by non-competitors. The position presented is 
certainly at odds with our own experience of action sports participants and suggests that the

sample may be biased towards an older generation, or media-focussed (as opposed to competitive-focussed) sample of performers. To our knowledge, most of the current top Finnish competitive snowboarders passed through the Vuokatti-Ruka Sports Academy coached by Pekka Koskela and Antti Koskinen including Olympic silver medallists Peetu Piiroinen and Enni Rukajarvi..." and have had plenty of coaching and structure present in both their formative and elite years" (P. Koskela, personal communication, June 21, 2015). Interestingly, Ojala and Thorpe (2015) cite Rukajärvi as stating that she “... might pass on the next Olympics" because she prefers styles of snowboarding which have more "soul" (p. 65). This is clearly supportive of multiple cultures within the sport, which our own work inherently acknowledges, but surely not indicative of an anti-coaching stance. This may suggest a need for a skill akin to cultural intelligence on the part of the coach (Peterson \& Brooks, 2004).

Finally, Ojala and Thorpe state categorically that "many of the most internationally recognized Finnish professional snowboarders have no affiliation with the FSA" (p. 66) the national governing body which provides coaching, science and funding support for performance. The absence of any data to support this contention, either qualitative or quantitative, is a clear weakness and would seem at odds with both the facts and perceptions we reported above.

Ojala and Thorpe also appear to present a rather narrow view of what coaching is. In fact, directly developing high end technical skills by telling/showing an athlete how to do a trick is one small facet of the work (cf. Willmott \& Collins, 2015). We would argue that, while definitions of coaching struggle with a lack of clarity (Collins \& Collins, 2012), this view is dated at best. Our studies highlight that shaping and driving the essential feedbackrich training environment is by far the more impactful role for most coaches we observe and 
work with in action sports. This is a long way from the "traditional, authoritarian" style which Ojala and Thorpe mention (p. 66) but which we have yet to observe in a high performance, action sports context. Based on our experience it simply wouldn't be tolerated and certainly would not be effective.

We were also interested to note that "if the coach is to be taken seriously with respect to enhancing snowboarding skills, he or she must have personally experienced and successfully performed the skills they are teaching" (p. 66). Our experiences of working with Bud Keene (coach to Shaun White, double Olympic and multiple X-Games gold medallist) and Hamish McKnight (coach to Billy Morgan, executor of the world's first quad-cork) would suggest otherwise. Indeed, any sport is going to be very limited in its progress if this perception of only teach what you can do were in any way universal. Surely, the point of any coach in any activity is to enable performers to exceed their own achievement. We would balance this with our own research highlighting that, in some action sports being undertaken for non-competitive participation, the coaches' developmental role is underpinned by a personal ability in the activity and environment for safety and contextual reasons. This personal ability is driven by a safety imperative and contextual driver, however; namely, the coach is traveling with the action sports participants into remote locations, providing a practical safety provision and coaching in context, (this differs from a purely guiding role). Our original point remains, however; any sport relies on coaches who can develop levels of skill higher than their own.

\section{Counterpoint 2: The Uncritical and Sole Promotion of PBL}

An effective coach will make use of a wide variety of coaching styles, using Professional Judgement and Decision Making skills (PJDM - Abraham \& Collins, 2011; Collins \& Collins, 2014, in press) to select the optimum tools for each specific context. As such, meaningful consideration of any potential coaching methodology (by implication from 
any source) should reflect a balanced, pros and cons approach. Medicine and education have a long engagement with PBL and provides an informed perspective on PBL's value. So where are the pitfalls and potential weaknesses of PBL?

Tan (2004), Wood (2003) and Morgan, Jones, Gilbourne and Llewellyn (2013) all highlight that inexperienced learners experience insecurities, stress and overload until they are familiar with the PBL process. While stresses and pressures need not be avoided, and are arguably an essential part of deep learning (cf. Bjork 1994) and the development of an expert performance (cf. Collins \& MacNamara, 2012), this does suggest three points: (a) that students at different stages of learning may require different teaching approaches, (b) that epistemological and ontological differences may present challenges, and (c) cultural perceptions of effective coaching are an important factor. The provision of declarative knowledge, at least in problem solving, will surely be required prior to its use (Tan 2004). The 'take home' being that, in fact, PBL does not meet everyone's needs all of the time. More importantly, the question of efficacy of PBL as a pedagogy also has to be considered. PBL potentially falls into the trap of being a fashion despite its 50 year history. We feel that this is an unwelcome tendency in coaching and education. Notably, Newman (2003) reduces these criticisms to a lack of high quality evidence, doubtful experimental design and the nuances of PBL in its application. The lack of empirical evidence necessitates greater research rather than assumptions on its validity in regard to PBL and its relevance and value in action sports coaching. The nuances associated in its application demonstrates a need for judgement and decision and supports our contention earlier that action sport coaching, in fact all coaching, is a PJDM based activity.

Interestingly, Butler, Inman and Lobb (2005) identify that PBL does not necessarily develop understanding. This may be an experimental design or application issue, but does raise the potential that PBL may not fit within the notions of constructivism despite its 
alignment with those philosophies. This appears to be supported by research that identifies that PBL does not foster application or integration of knowledge, build on existing learning, develop forward reasoning or cognitive abilities (Morrison, 2004; Walsh, 2005). Admittedly, these views are challenged (cf. Vernon \& Blake, 1993; Albanese \& Michell, 1993, Norman \& Schmidt, 2000) but the jury is definitely out in this respect. At best, Morrison, (2004), Moust et al, (2005), Morgan, Jones, Gilbourne and Llewellyn (2013) and Newman, (2003) highlight that more research is needed (echoing our position) that findings for the efficacy of PBL are inconclusive.

Finally, both Norman and Schmidt, (2000) and Colliver (2000) comment that PBL has been 'over sold' by its advocates and identify that "any study that treats PBL as a single intervention and examines the usual cognitive and clinical outcomes will arrive at a conclusion of minimal difference" (Norman \& Schmidt, 2000, p. 727). Against such critique, its' use has to clearly be more carefully considered and investigated. Consequently, and in the present context, we would question the positive picture of PBL which Ojala and Thorpe (2015) provide and encourage two further considerations, (1) a more pragmatic approach to its application based on evidence and further research and (2) consideration of PBL alongside other pedagogies.

\section{Conclusion}

Action sports present the coach and research with a new array of challenges.

Developing a body of knowledge that relates to action sports is a common goal of both our investigation and that of Ojala and Thorpe. Within this emerging culture a healthy academic debate is essential. We contend that Ojala and Thorpe's (2015, cf. p. 68), engagement with a single group prevents understanding of broader trends, and different ways of knowing. We observe that, based on the two issues we have raised, such limitations are apparent in the perspectives provided. As an example of the limitations, they cite Hmelo-Silver and 
126 Eberbach (2012) on the goals of PBL as being to develop (a) flexible knowledge, (b)

127 effective problem-solving skills, (c) effective self-directed learning skills, (d) effective

128 collaboration skills, and (e) intrinsic motivation. We would have to observe that, far from

129 being the sole preserve of PBL, this summarises all good coaching. So, in summary, and as a

130 means to stimulate debate, we suggest that:

131 - culture is an important factor in coaching any sport, not just the action ones.

132 - action sport athletes may be far more accepting, indeed desirous, of good coaching

133 than Ojala and Thorpe suggest;

134

- $\mathrm{PBL}$ is one technique of many that are appropriate to coaching any athlete, the decision to use the right tool in the right place at the right time with the right person being the pivotal factors in good coaching.

137 We look forward to further research and debate in this area. 
140 Abraham, A., \& Collins, D.J. (1998). Examining and extending research in coach development. Quest, 50, 59-79.

Abraham, A. \& Collins, D. (2011). Taking the next step: Ways forward for coaching science. Quest, 63, 366-384. 
Colliver, J. (2000). Effectiveness of problem-based learning curricula: Research and theory. Academic Medicine, 75, 259-266.

Hmelo-Silver, C.E., \& Eberbach, C. (2012). Learning theories and problem-based learning. In S. Bridges, C. McGrath, \& T. Whitehill (Eds.), Researching problem-based learning in clinical education: The next generation (pp. 3-17). New York: Springer.

Morrison, J. (2004). Where now for problem based learning? The Lancet, 363(9403), 174.

Moust, J.H.C., van Berkel, H.J.M., \& Schmidt, H.G. (2005). Signs of erosion: Reflections on three decades of problem-based learning at Maastricht University. Higher Education, 50(4), 665-683.

Newman, M. (2003). A pilot systematic review and meta-analysis on the effectiveness of problem based learning. Newcastle: Learning \& Teaching Subject Network. Retrieved from http://citeseerx.ist.psu.edu/viewdoc/download?doi=10.1.1.133.6561\&rep=rep1\&type= pdf viewed 05/05/2015

Norman, G, R, \& Schmidt, H, G. (2000). Effectiveness of problem based learning curricula: Theory, practice and paper data. Medical Education. 34, 721-728

Ojala, A-L \& Thorpe, H. (2015). The role of the coach in action sports: Using a problembased learning approach. International Sport Coaching Journal, 2, 64-71. http://dx.doi.org/10.1123/iscj.2014-0096.

Stoszkowski, J. \& Collins, D. (2014). Communities of practice, social learning and networks: Exploiting the social side of coach development. Sport, Education and Society, 19(6), 773-788.

Tan, O.S. (2004). Students' experiences in problem-based learning: Three blind mice episode or educational innovation? Innovations in Education \& Teaching International, 41(2), 169-184. 
189 Vernon, D. T. A., \& Blake, R. L. (1993). Does problem-based learning work? A metaanalysis of evaluative research. Academic Medicine, 68, 550-563.

191 Walsh, A. (2005). The tutor in problem based learning: An opportunity for theatre nurse education. British Journal of Theatre Nursing, 9(11), 531-536

193 Willmott, T. \& Collins, D. (2015). Challenges in the Transition to Mainstream: Promoting Progress and Minimizing Injury in Freeskiing and Snowboarding. Sport in Society, http://dx.doi.org/10.1080/17430437.2015.1031530

196 Wood, D. (2003). Problem based learning. British Medical Journal, 326(7384), 328-330. 